\title{
Rebalancing interests and power structures on crowdworking platforms
}

\author{
Ayad Al-Ani \\ Humboldt Institute for Internet and Society (HIIG),Berlin, Germany, ayad.al-ani@hiig.de \\ Stefan Stumpp \\ Humboldt Institute for Internet and Society (HIIG),Berlin, Germany, stumpp@hiig.de
}

Published on 30 Jun 2016 | DOI: 10.14763/2016.2.415

\begin{abstract}
Crowdwork on virtual platforms is developing into a recognisable employment and business model on the internet. Despite their many differences, the platforms that have emerged over the last few years have one thing in common: a crowd of individual producers and capabilities is mobilised - in the form of labour, accommodation or durable goods - onto the market in cooperation and competition with firms from traditional industries. This study analyses the factors crowdworkers consider relevant in their work and the measures they view as helpful in improving their working relationship with platforms. It is apparent that, in the best tradition of the peer economy, this new type of worker still considers learning and fun important factors for his or her engagement. Despite these effectively intrinsic factors, workers are quite aware of their situation, which does not put them on equal terms with the platform's algorithms and customer focus. This awareness of power disparities does not lead them, however, to reconsider their effectiveness when it comes to renegotiating terms with the platform: when specifically asked about the role of unions, the majority of crowdworkers did not expect help in self-organisation from these institutions. Considering the difficulties in regulating the market for platforms, (self-) organisation of crowdworkers, however, is an important prerequisite in rebalancing the power structure dominated by platform owners and their customers. Selforganisation is something digital natives are quite familiar with and we have to assume that crowdworkers are perhaps overconfident in their abilities. And due to the novelty of this industry, this confidence has not been shaken yet by labour disputes or even by growing dissatisfaction with platforms.
\end{abstract}

Keywords: Crowdworking, Crowdsourcing, Sharing economy 


\section{Article information}

Received: 01 Feb 2016 Reviewed: 12 Apr 2016 Published: 30 Jun 2016

Licence: Creative Commons Attribution 3.0 Germany

Competing interests: The author has declared that no competing interests exist that have influenced

the text.

URL:

http://policyreview.info/articles/analysis/rebalancing-interests-and-power-structures-crowdworking-pl atforms

Citation: Al-Ani, A. \& Stumpp, S. (2016). Rebalancing interests and power structures on crowdworking platforms. Internet Policy Review, 5(2). https://doi.org/10.14763/2016.2.415

This paper is part of Regulating the sharing economy, a special issue of Internet Policy Review guest-edited by Kristofer Erickson and Inge Sørensen.

Disclaimer: This study was completed with the support of the German service sector union ver.di. We would like to thank the participating platforms and their communities for the opportunity to conduct a survey. We would also like to thank the jovoto platform for the implementation of an idea contest. Thanks also go to Prof. Dr. Christian Fieseler, BI Norwegian Business School and Prof. Dr. Wrona, TU Hamburg-Harburg, for their comments and reviews. Any errors remain the responsibility of the authors.

\section{INTRODUCTION AND OBJECTIVES}

Working on virtual platforms, whose function is to match up the skills of sellers with assignments set by buyers, is a new phenomenon. In uncertain economic times in which longterm planning is not possible, tasks, resources and skills must be marshalled, ad hoc and at short notice. The resulting "pull economy" differs from the traditional "push economy", which allocated these resources on the basis of supposedly accurate plans and sought to develop them (Hagel et al., 2010, pp. 31 ff.; Bauwens et al., 2012, pp. 29 ff.). Now, traditional companies increasingly use platforms to quickly access needed skills from external sources, boosting their capacities (Al-Ani, 2013, pp. 89 ff.). This "cooperation" between the platform and the hierarchy is needed to solve a pressing dilemma for the firm: on the one hand, companies are subject to cost pressures due to globalisation and hyper-competition; on the other hand, there is a lack of innovative abilities in the traditional lean hierarchies: cost cutting has limited their capacity to create ideas and to conduct experiments (Hamel, 2007, pp. $45 \mathrm{ff}$.). In this situation, it is precisely the innovative, cost-conscious and almost inexhaustible power of the crowd, accessed via platforms without negatively impacting the company's cost structure, that seems to have become a new core competency of the firm (explore \& exploit). Not surprisingly, a variety of pull platforms, which integrate the crowd's labour and innovative power into the company's value chain, have emerged (Hagel et al., 2010, pp. $61 \mathrm{ff}$.).

While a number of reflections on the mechanics and functioning of these commercial platforms have emerged in recent times, we lack deeper insights into the new employment relations that have appeared as a result.1 The present study examines what determining factors crowdworkers 
consider relevant in their work and, above all, what support measures they anticipate to be useful in improving their working relationship with the platform.

\section{PRELUDE: THE RISE OF THE P2P PLATFORM}

In the software industry of the 1990s, salaried programmers came together in their spare time to work on interesting, unpaid projects on custom-built platforms. These employees switched roles after the working day finished and mutated into "free producers", into peers, who, together with other free producers, could do more, not just for themselves, but above all with other people (Benkler, 2006, p. 9). New principles of cooperation emerged: the intrinsically motivated peers worked in a self-directed manner and autonomously sought out their challenges.2 On the basis of an often given "core", thousands of programmers sought and found opportunities to participate in such open source projects all around the world. The results of these collaborations were made available free of charge as commons, and everyone was invited to participate in improving them (Bauwens, 2005). These new peer-to-peer ( $\mathrm{P} 2 \mathrm{P})$ collaboration platforms had extremely flat organisational structures.3 This does not mean that there were no hierarchies. However, within the $\mathrm{P} 2 \mathrm{P}$ environment, these levels are used to secure the mostly open access to the platform and to protect the contributors; they are not intended to enforce exclusivity: 'An important clarification is that when we say that peer to peer systems have no hierarchy or are not centralized, we do not necessarily mean the complete absence of such characteristics. But in a P2P system, the use of hierarchy and centralization, serve the goal of participation and many-to-many communication, and are not used to prohibit or dominate it.' (ibid). The working principle of these platforms can be defined as a meritocracy: peers are mainly assessed by other peers based on their contributions. This feedback alone allows them to rise to a new role with more responsibility (ibid). If an individual's contribution diminishes, the role is relinquished. A paradoxical principle arises: a highly individualised form of organisation, in which individuality plays a major role while the individual plays a small part.

\section{PLATFORMS AS PARTNERS AND COMPETITORS OF THE FIRM}

The obvious success of $\mathrm{P}_{2} \mathrm{P}$ platforms (Wikipedia, Linux, etc.) also led to a growing interest among companies in this form of organisation and especially in the capacities of peers, who usually worked free of charge.4 To create a needed interface between companies and peers, commercial platforms have emerged, which have "interpreted" or rather re-interpreted the basic principles of P2P platforms (self-identification, self-management, meritocracy) in a commercial context. Covering a wide array of needs, these platforms differ quite significantly in their functioning and thus also in the kind of crowdwork that takes place on them (Al-Ani, 2015, pp. $11 \mathrm{ff.}$; Al-Ani and Stumpp, 2015, pp. 24 ff.):

- Efficiency platforms: these platforms assign small-scale work packages from contracting companies to interested crowdworkers. The work packages range from less complex tasks, such as those offered through the well-known platform Mechanical Turk, to the evaluation of seminar papers, and even complex medical reports. 5

- Innovation platforms: on these platforms, companies advertise issues to be solved using the framework and logic of "competitions"; the "winners" are rewarded with a bonus. This category includes scientific-problem-solving platforms like InnoCentive, creative platforms like jovoto and software development platforms like TopCoder. 
- Agency platforms: on these types of platforms, mediated resources - and not work outcomes - are in the foreground. Agency platforms source particular skills or rather employees for contracting companies. The employees sourced in this manner subsequently act as freelancers rather than crowdworkers within the traditional client enterprise: they are not managed via the platform's algorithm, but directly via the firm's hierarchy. Examples of this include the platforms Elance, Twago, oDesk or Jomondo.The path from these agency platforms to "real" crowdsourcing platforms is not a very long one. It is obvious that an extension of the business model sooner or later may involve taking on the task of managing freelancers for the client.

In contrast to the original $\mathrm{P} 2 \mathrm{P}$ platforms, the "commercialised" platforms led to significant changes for the participating peers, who mutated into crowdworkers who:

- Are paid for their activities, at least for a bid (winning a tender) or if a predefined goal is achieved (e.g. finding a software error).

- No longer collaborate with others in a self-managed manner, but are instead individually allocated, directed and remunerated based on the procedures or algorithms of the commercial platform: self-management is repressed and is only possible within narrowly outlined steps, which leads to a power asymmetry at the crowdworkers' expense. The algorithm determines what work will be accepted and carried out under what conditions and thus restricts contingency significantly: "Working conditions in digital workplaces appear to be characterized by a smaller tolerance for failure and mistakes. More strikingly, platforms that mediate digital work severely limit the scope and potential outcomes of negotiations. Workers can accept tasks and supply results, and requesters can define and allocate tasks and accept or reject results. These basic platform settings also limit the negotiation opportunities of requesters, but workers systematically find themselves in a weaker bargaining position because the power to sanction perceived misbehaviour rests squarely with the requesters." (Bucher, Fieseler and Hoffmann, 2015, p. 14 f.).

- Interact with a platform company which intermediates between the client and the crowdworker.

This said, platforms do not necessarily have to confine themselves to being sourcing partners for companies. Platforms are increasingly becoming competitors to private sector companies. Here, the combination of the peers' work capacity with particular assets owned by the independent producers (cars, rooms, etc.), results in a "new" product or service that is provided to the market through the platform (Manjoo, 2015). This can create unique and disruptive situations on the market, since from one day to the next, both the peers' working capacities and their thus-far commercially unused assets are brought onto the market (Uber, Airbnb, etc.) via platforms. These compete with existing providers in the transport, hotel and media industries quite successfully, since these platforms are often able to draw on the high commitment of the crowdworker, who has mutated into a micro-entrepreneur, as well as the lower overhead costs, high flexibility and innovative customer interfaces (ibid.). Clearly, this "flexibility" is also due to the policy of these platforms, which often do not treat their producers as employees in the traditional sense. In extreme cases the commercial platform accepts no liability for the actual market transaction, but charges a commission of between five and 20 per cent for initiating and mediating the agreement between the producer and the client.6 It is therefore not surprising, that despite the ongoing "monetisation" of the original P2P idea, commercial platforms are often still regarded as a neutral party positioned between clients and crowdworkers.7

\section{LESSONS LEARNED SO FAR: HISTORY REMAINS}

Due to the widespread impact of new forms of working practice and organisation, there has been considerable interest from institutionalised research, and in particular from a vanguard of popular science and business management writers.8 On top of that, the P2P movement has 
institutionalised itself as a complex of interests on its own platforms, which encourage and support the development of scientific content in the spirit of $\mathrm{P}_{2} \mathrm{P}$ ( $\mathrm{P}_{2} \mathrm{P}$ Foundation, n.d.a.). In recent times, the growing strength of some platforms, which have emerged as competitors to companies, has added an important topic to the research agenda.9

The findings of these studies can be summarised as follows: on P2P platforms such as Wikipedia and open software platforms such as Linux, intrinsic motivation, self-management and selfidentification with tasks are dominant factors. Workers who have "escaped" from hierarchical organisations grasp the opportunity to finally do the things they want and thereby enjoy the appreciation of other peers.10 Although $\mathrm{P} 2 \mathrm{P}$ platforms are aligned with the principles of selfmanagement and self-identification, they are not free of hierarchies, and do indeed have procedures, algorithms and management principles. However, the function of such control loops differs from the function of similar systems in hierarchical organisations, because the mechanisms are not there to establish exclusivity, but rather intend to achieve meritocracy, openness and cooperation: "[...] $\mathrm{P}_{2} \mathrm{P}$ is a democratic process of full inclusion based on the idea of equipotency. It believes that expertise cannot be located beforehand, and thus general and open participation is the rule. But selection immediately sets in as well, since the equipotency is immediately verified by work in the project. Thus there is a selection before the project, and a hierarchy of networks is created, where everyone finds his place according to demonstrated potential. Within the project, a hierarchy is also immediately created depending on expertise, engagement and the capacity to generate trust. [...] Peer to Peer is not anti-hierarchy or even anti-authority, but it is against fixed hierarchies and 'authoritarianism' [...]." (Bauwens, 2005). Commercial platforms have adopted the structural elements of P2P systems and have begun marketing their peers-turned-producers' services and focusing even more closely on customers' requirements. Despite this restriction of self-determination, even on commercial platforms like Mechanical Turk and Uber, elements of the $\mathrm{P}_{2} \mathrm{P}$ paradigms still seem to be influencing the motivations of the crowdworkers: fun and learning experiences, for instance, are still of considerable importance and often outweigh commercial considerations.11 Yet, this transformation of the commons based $\mathrm{P} 2 \mathrm{P}$ production into a commercial enterprise begins to provoke reactions of the producers. There are some initial indicators that the dissatisfaction with the existing power asymmetries on commercial platforms will increase with the length of time spent on the platform.12

\section{DESIGN OF THE STUDY}

This study is based on an explorative two-step process, which is composed of expert interviews in the form of a workshop and a quantitative online survey.

\section{OPENING THE FIELD: THE EXPERT WORKSHOP}

At the beginning of the research project in June 2015, an expert workshop was conducted for platform representatives, representatives of trade unions and scholars to address the phenomenon of crowdworking. First, the typologies of individual commercial platforms were analysed, and scenarios were outlined for trade union support of crowdworkers based on international experience (Al-Ani and Stumpp, 2015). Based on this discussion, the strategy for the present study was developed. We selected two platforms - an efficiency and an innovation platform, and subsequently two target groups of crowdworkers - creatives and IT developers and testers - to cover the greatest possible range of different crowdworkers and platforms. These target groups were to be asked about their motivations and their requests for improved 
working conditions on the respective platforms. The intention was also to examine whether there are concrete demands for unions to optimise these conditions.

\section{QUANTITATIVE ONLINE SURVEY}

Participants in the online survey were crowdworkers from the platform jovoto.13 and an anonymised efficiency crowdworking platform. jovoto is an innovation platform for creative people, particularly those who design objects and create communications strategies. The jovoto community has an international scope. The sample in this case is made up of a total of 20 nationalities. By contrast, crowdworkers on the efficiency crowdworking platform test software for applications, websites, desktop applications, etc.. Here, one could assume that community members have a computer science background. The community on the efficiency platform is internationally oriented, but for practical reasons only German-speaking users were surveyed. Participants were approached in the course of a notification on jovoto, which was sent to the entire group. On the IT platform, the respondents were contacted via the community managers. The survey was conducted in the period from 15 September 2015 to 30 October 2015. The sample size for the efficiency platform was $n=93$ and for jovoto, it was $n=72$ crowdworkers. The participants in the sample from the efficiency platform are henceforth referred to as the IT crowd, while the participants from jovoto are referred to as the creative crowd. The questionnaire used in this sample consisted of both open-ended and also Likert-type scale questions. We asked participants to fill out questions about their sociodemographic information, current working situation, their motivations and also their expectations about support mechanisms for crowdworking.

\section{FUN AND LEARNING EFFECTS, THE MAIN DRIVERS OF CROWDWORKING: DATA ANALYSIS AND RESULTS}

\section{SOCIODEMOGRAPHICS AND TIME SPENT CROWDWORKING}

Crowdworkers in our two samples are predominantly male, young and well-educated. The proportion of male crowdworkers in the sample is 67.7 per cent for the IT crowd and 51.4 per cent for the creative crowd. Most of the crowdworkers are up to 34 years of age. The 50+ age group, by contrast, is a minority. The differences between the two groups, the IT crowd and creative crowd, are relatively low in the age groups represented.

For the educational levels, too, the results are clear. On both platforms, the crowdworkers are well-educated and have either completed a university degree or have at least a higher secondary-level certificate that qualifies them to enter university. 


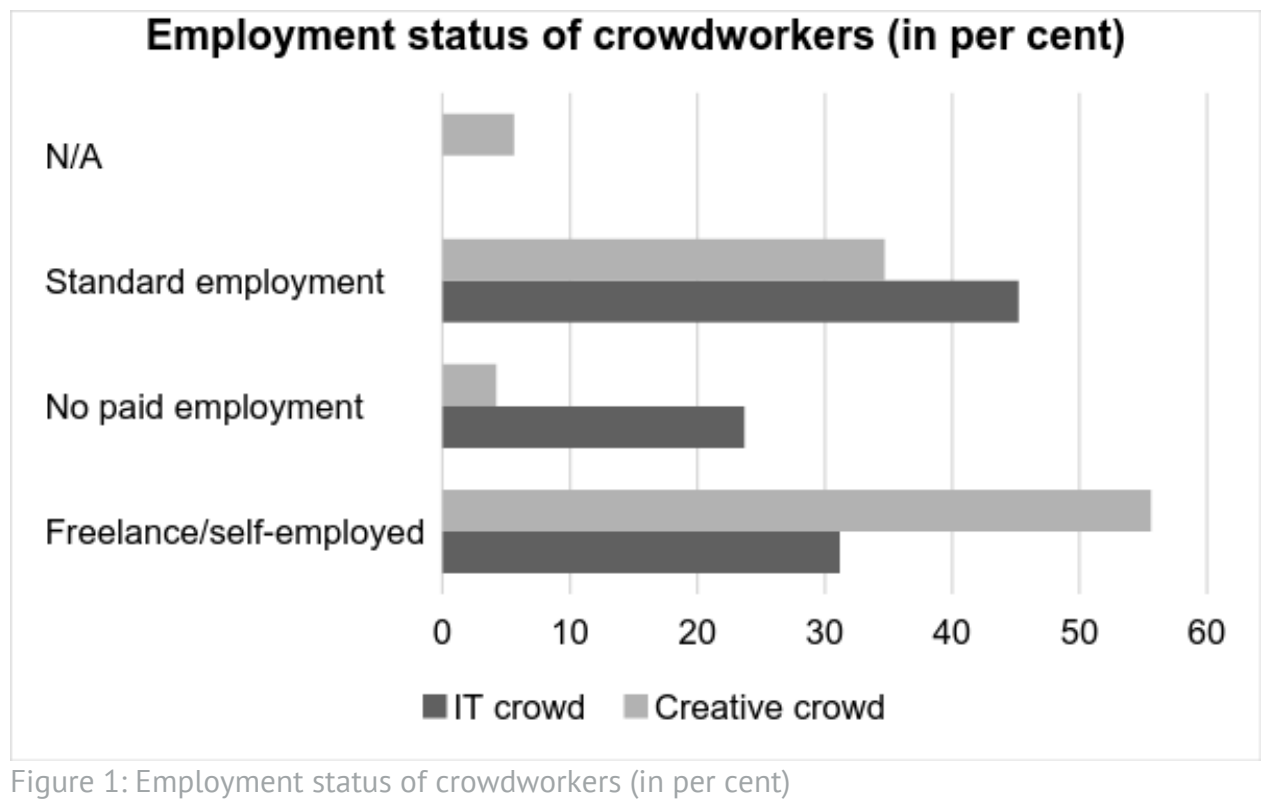

What is particularly notable for the two groups is that a very high share of these individuals work on standard contracts elsewhere - 45 per cent of IT crowdworkers report this status and about 35 per cent of the creatives (see Figure 1). In addition to explaining the higher payment for IT services, this may also explain the better income situation of IT crowdworkers: while only 18 per cent of the creative crowd earn a net household income of more than 3.000 euros a month, at least 31.2 percent of the IT crowd have earnings above this level.

There are other differences that are apparent in the monthly investment of time. The creative crowd invests significantly less time in hours per month than the IT crowd (see Figure 2). Meanwhile, a large percentage of users within the IT crowd invests eleven to 40 hours per month. Again, this is probably also an indicator that platform work is becoming or has already become part of the work- and lifestyle in the IT sector.

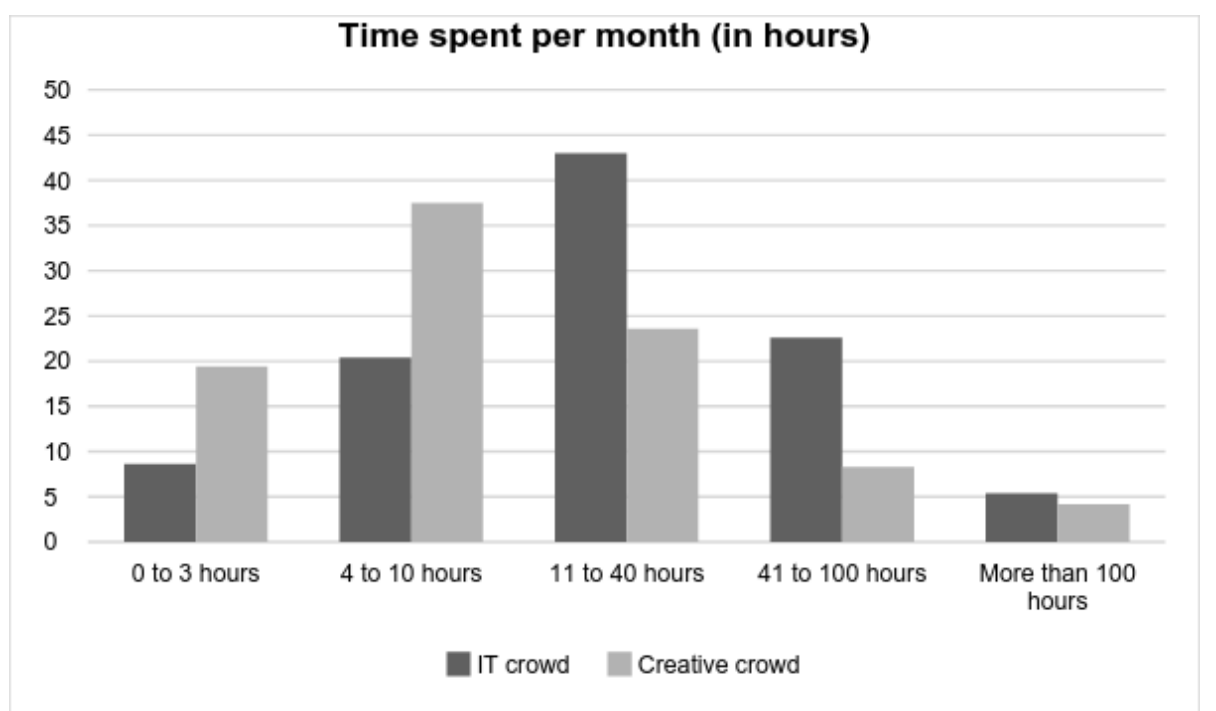

Figure 2: Time spent crowdworking per month (in hours)

\section{MOTIVATIONS OF CROWDWORKERS}

Surprisingly, however, the socioeconomic differences have no fundamental impact on the respondents' motivations. On both platforms the motivating factor "fun" is ranked most 
important, followed by "additional income" (see Figure 3). On the one hand, this result may be an echo of the P2P traditions, but on the other hand, it may be explained by the feedback that only a minority of interviewed persons can earn a living by working on these platforms (see Figure 3).

$\mathbf{x}$

Figure 3: Motivations of the crowdworkers (in percent): the scaling of the response options ranges from "I agree completely" to "I strongly disagree" (1-4). The chart shows the cumulative responses "I agree completely" and "I somewhat agree".

In addition to the almost identical motivation present in both groups - "to gain appreciation" in both platforms, learning new skills was also a very prominent factor. Creative crowdworkers seem to use these platforms to an even greater degree to build up their reputation and to instrumentalise or practice entrepreneurial knowledge. Obviously, the opportunity to build up a market reputation on the platform is more important for this group than for the IT crowd.14 Here, a number of participants mentioned access to interesting customers, brands and projects. Clearly, the advantage of innovation platforms is that crowdworkers have the opportunity to obtain access to projects or clients and brands that they would normally not encounter in their regular employment relationship. The relevance of platform work for hedonistic motivations and also for learning new skills enabled by meritocracy is also reflected here in the comments of the respondents (see Table 1). In addition, the higher temporal and geographical flexibility of this work is evidently a further advantage.15

Table 1: Comments from crowdworkers about their motivations, as provided in open answer fields (own translation)

\begin{tabular}{|l|l|}
\hline Motivation & \multicolumn{1}{c|}{ Answers (quotes) } \\
\hline \multirow{2}{*}{$\begin{array}{c}\text { Fun and } \\
\text { interest }\end{array}$} & $\begin{array}{l}\text { "Product/website optimisation and testing is exciting, very interesting and } \\
\text { multifaceted." }\end{array}$ \\
\cline { 2 - 3 } & $\begin{array}{l}\text { "To meet new people, know what is happening on the app market, } \\
\text { interesting projects with fresh ideas" }\end{array}$ \\
\cline { 2 - 3 } & $\begin{array}{l}\text { "Fun to see new stuff before the initial release and be aware of new } \\
\text { technologies (e.g. hbbTV)" }\end{array}$ \\
\cline { 2 - 3 } & $\begin{array}{l}\text { "I'm pretty good as a software tester, I can help to improve apps and } \\
\text { programs and I have fun doing it." }\end{array}$ \\
\cline { 2 - 3 } & $\begin{array}{l}\text { "Competition among the participants. It's fun to outdo the other testers in } \\
\text { skill." }\end{array}$ \\
\cline { 2 - 3 } & "See my ideas working." \\
\cline { 2 - 3 } & "I enjoy creative work" \\
\cline { 2 - 3 } & $\begin{array}{l}\text { "As a hobby for leisure \& help the needy (Unicef, refugees) through design } \\
\text { \& art. It is something I can do \& contribute to help others." }\end{array}$ \\
\hline \begin{tabular}{l} 
"Creative freedom" \\
\hline
\end{tabular}
\end{tabular}




\begin{tabular}{|c|c|}
\hline Motivation & Answers (quotes) \\
\hline \multirow[t]{5}{*}{ Learning } & $\begin{array}{l}\text { "Improving language skills, for example, English. Improve my ability to } \\
\text { express myself or describe things." }\end{array}$ \\
\hline & "I learn about new interesting programs, websites etc. before the release." \\
\hline & "I benefit from getting more experience as a tester" \\
\hline & "Self-development” \\
\hline & "I learn about new topics" \\
\hline \multirow[t]{7}{*}{ Flexibility } & “... because I can allocate my time myself.” \\
\hline & "Working from home and earning extra money" \\
\hline & "Work that is not tied to one location" \\
\hline & $\begin{array}{l}\text { "To date, nobody has asked me about my age or career path. If I do a good } \\
\text { job on the platform, I get more jobs. No matter what was before." }\end{array}$ \\
\hline & $\begin{array}{l}\text { "Because of my children, I can work only from home. Crowdworking is a } \\
\text { very flexible way of working." }\end{array}$ \\
\hline & $\begin{array}{l}\text { "For me as a workaholic, it is a wonderful substitute for employment } \\
\text { during the holidays." }\end{array}$ \\
\hline & $\begin{array}{l}\text { "Diversity of projects I can take part in. I can work anywhere, anytime, and } \\
\text { however I want." }\end{array}$ \\
\hline
\end{tabular}

\section{HOW CAN CROWDWORKING CONDITIONS BE IMPROVED?}

When asked how other actors can support the work done by crowdworkers, the respondents, not surprisingly, largely assessed all the listed possibilities as reasonable - albeit to a greater or lesser degree. This generally positive assessment may have something to do with the participants' relatively brief experience, which limits their ability to assess the costs and benefits of these supporting strategies.16 In addition to providing ways of evaluating platforms, this especially involved developing their own community, which, as a kind of shadow organisation, would reintroduce the connections between crowdworkers that were suppressed by platforms.17 Just establishing an independent rating system to track the reputation of crowdworkers, found slightly less support. 
Strategies for supporting crowdwork

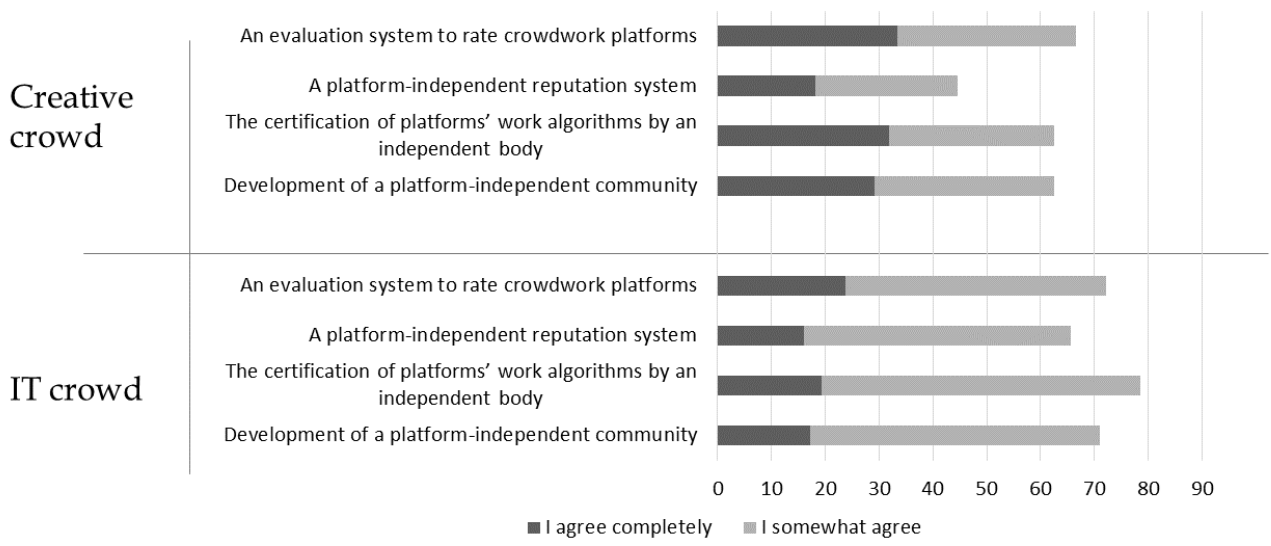

Figure 4: Strategies for supporting crowdwork (in per cent)

What is initially surprising in this analysis is the finding that the respondents - and here the IT crowd is a bit more supportive - strongly favoured more transparency and a certification of algorithms of platforms. However, when one considers the central role of algorithms in the control of crowdworkers, this requirement is more than understandable. And the fact that the IT crowd viewed this issue as the most urgent comes as no surprise because of the familiarity of this group with IT functionality.

An open response field gave the respondents an opportunity to express their expectations towards supporting mechanisms for crowdworkers. It is striking that the respondents have a critical attitude towards rating mechanisms due to the risk of fake reviews. It is also obvious that there is a demand for a system to determine a fair wage for the crowdwork done. Besides considering the technical requirements, there is also a demand for work appreciation and a kind of lobbying work for crowdworkers (see Table 2).

Table 2: Comments from crowdworkers about their expectations of supporting crowdwork 


\begin{tabular}{|c|c|}
\hline & Answers \\
\hline \multirow[t]{5}{*}{$\begin{array}{l}\text { Various } \\
\text { expectations of } \\
\text { crowdworking } \\
\text { support }\end{array}$} & $\begin{array}{l}\text { "Note: black sheep (e.g. clickworkers) will ensure that they get every } \\
\text { quality seal, } 5 \text { stars everywhere and masses of users who write them } \\
\text { fabulous reviews (if necessary, for } 1.32 \text { euros/40o words :o)). And } \\
\text { stringent control measures would only over-complicate everything and } \\
\text { thus take the most positive feature out of crowdworking." }\end{array}$ \\
\hline & "A system for determining the actual hourly rate" \\
\hline & $\begin{array}{l}\text { "There should be a kind of hourly wage, which is implemented via test } \\
\text { cases. At present, I am only paid if I find errors. This means the pay } \\
\text { varies greatly. On most crowdsourcing platforms, I feel really } \\
\text { underpaid." }\end{array}$ \\
\hline & $\begin{array}{l}\text { "For me, the most important thing would be that the work is } \\
\text { appreciated. By the staff members of the platform, the customer and } \\
\text { society. A lot of people gain a lot of experience in this work and do a } \\
\text { very good job, and many have good reasons why they want to work like } \\
\text { this. But this form of work is often really ridiculed and dismissed as } \\
\text { inferior. The reputation of the crowdworkers and their work should be } \\
\text { improved in general, something like lobbying, public relations,..." }\end{array}$ \\
\hline & $\begin{array}{l}\text { "A comforter, to praise, console \& help develop positive energy, } \\
\text { especially those who haven't win \& keep trying." }\end{array}$ \\
\hline
\end{tabular}

\section{IS THERE A POTENTIAL ROLE FOR TRADITIONAL TRADE UNIONS?}

Trade unions could act as partners of crowdworkers and help them fulfil some of the mentioned requirements. When crowdworkers think about trade union support, they often think of tasks like providing advice, which is already offered today.18 The fact that there is a demand for a neutral or conflict-mediating body indicates that the above-described dilemmas of corporate platforms and their power asymmetries have become more apparent. This situation may act as an incentive for trade unions to extend their traditional range of services and skills; in order to take on these roles, unions have to understand and deconstruct the mechanics and algorithms of the platform in the same manner as they evaluate firms' business processes and IT solutions today. These new skills, in turn, could then be used to provide certification for platforms by the union, an idea which is supported by nearly one-third of respondents (see Figure 5).

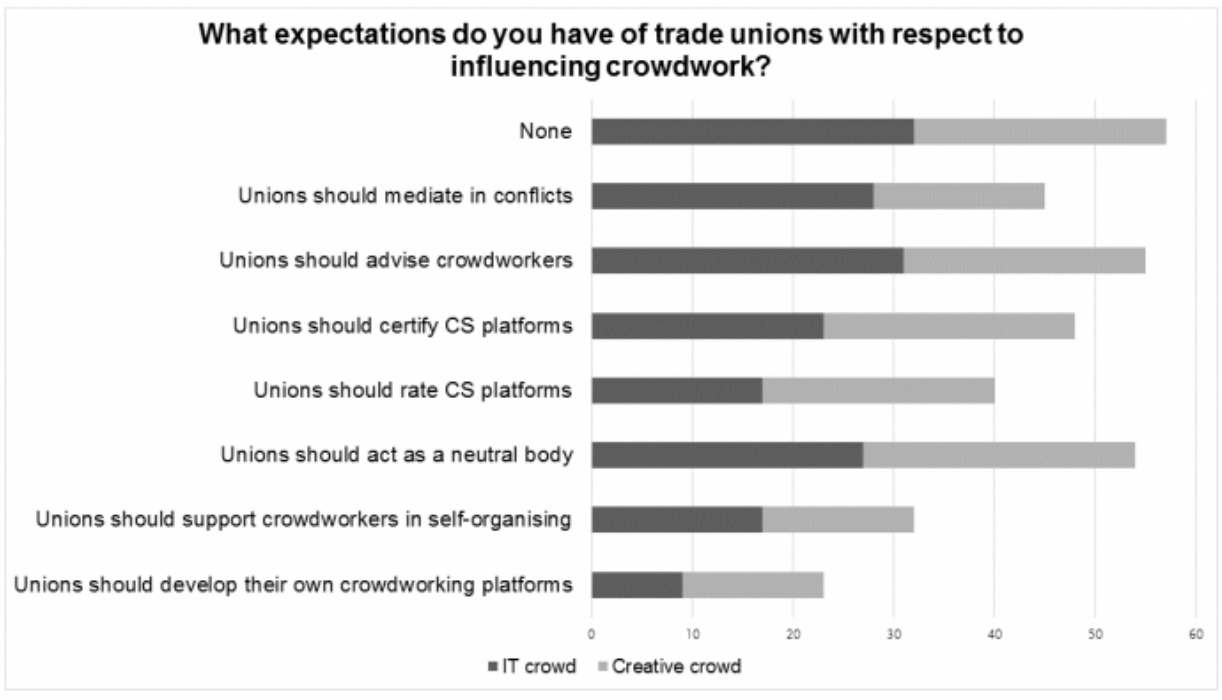


Figure 5: Expectations of a union (in reply frequencies)

However, there is another traditional role of trade unions that is apparently not demanded by crowdworkers in our sample: that of advocacy. The lowest expectations related to support for worker self-organisation and the union organisation of groups of crowdworkers. This may have something to do with the "de-institutionalised" self-organisational abilities of crowdworkers, who can act via shadow organisations or rather, shadow platforms that are very similar to the original P2P (self-)organisations (Bauwens, 2005).

At this point, it seems justified to speculate about the abilities of crowdworkers to build bargaining power effectively. Some initial experiences, for instance with the Amazon Mechanical Turk platform, seem to show that self-organisation is a rather complex undertaking: self-organisation manoeuvres between the risk of being too passive and not offering enough stimulation to members to join in (stall) or having to deal with too many different interests and collapsing under the weight of contradictions (friction).19 Still, as crowdworkers clearly acknowledge their position on the platform as not being equal to the platform owners and customers, we can expect self-organisation experiences and bargaining processes to increase over time.2o If currently specialised organisations like unions are finally able to connect with these self-organised bodies, as happened in the Uber California cas.21, this will, we suspect, only be possible after intensive rearrangements and change processes in the political sphere that surrounds the digital economy, of which unions are a part of.22

\section{CONCLUSION AND DISCUSSION}

From a crowdworker's perspective, platforms today operate as a kind of learning laboratory: people upgrade their reputations and knowledge, which they can then use and monetise in selfemployment, but also in standard employment. Work on platforms thus becomes part of an individualised learning path for people who are continuously learning "on the job”. ${ }_{23}$ Of course, pay plays an important role, but not in the sense of earning enough to live but rather as additional income to secure and support the crowdworkers' existing living situations. To that extent, a discussion that overemphasised the precariat would narrow down the issue too much, because the motivations for and the effects of crowdworking today are in very different areas, and crowdworking in fact compensates for certain deficits in traditional working life (rigid, inflexible learning opportunities, economic inequality, hierarchical organisations, division of labour, restrictive development opportunities, seniority and elitism, etc.). However, on this point, it is interesting to note that the criticism of crowdworking has not led to a related discussion of the shortcomings of traditional companies and educational paths. It is these very deficits that make crowdworking attractive, despite its limitations and asymmetries.

The novelty of crowdworking suggests that the crowdworkers' demands concerning the fairness of the platforms, as well as the search for and the development of alternatives will increase in the next few years. Over time, the ability of the crowd to analyse asymmetries and to develop counter-strategies will also expand. It should also not be forgotten that, given its propensity for self-organisation, the crowd always has the inherent potential to develop its own business models, if the dissatisfaction with what its members encounter is too great. For those working in the virtual world, the option to exit always means building something of one's own, perhaps even with the help of trade unions.24 Alternatives arise when one decides to flee: "To resist is to create!..25 Viewed in this manner, we suspect that commercial platforms do not necessarily have to participate in a rat race, but instead may attempt to increase their attractiveness by offering 
crowdworkers additional functions (social benefits, training, etc.).

The transparency of platforms requires the development of analytical and evaluation skills as well as new rules for the participants of the digital economy. The fairness of the distribution and of the procedures requires the ability to decode and evaluate algorithms. As recent examples from the automotive industry show, however, opening the relevant programming is a delicate and difficult matter, because abuse is possible and competitive advantage may be lost.26 In this regard, trade unions could be active as neutral and independent bodies: they need to develop skills in decrypting algorithms so that they can provide competent advice and mediation and thus act as certifiers of platform procedures. This would counter the danger of competitive disadvantages for the opening of platforms and would signal to crowdworkers that the algorithm is based on fair criteria.27

Knowledge about the effects of algorithms, however, is of little use, if crowdworkers cannot increase their bargaining power to assert their demands to the platform owners. For crowdworkers, the community is obviously an important element. It promises protection, or rather help and assistance, or at least the feeling of being part of a greater whole, which is composed of different individuals who share similar life situations (Bollier, 2014). Furthermore, considering the difficulties of imposing regulations on entities such as platforms - which use a workforce from various regions of the world and whose "location" can easily move from one place to the other - the importance of self-organisation in the virtual space and at physical locations becomes a key factor.28 At the same time, crowdworkers do not seem to consider the organisational capacity of unions, which may have something to do with the novelty of the relationship between crowdworkers and the unions, but also with this group's inherent capacity for self-organisation. Initial experiences with platforms like Amazon Mechanical Turk and Uber, however, show that self-organising crowdworkers for political conflict is a rather complex undertaking. From this perspective, trade unions have the opportunity or challenge to support these self-organisational capacities with appropriate services. For the moment, it seems unlikely that crowdworkers will use unions as the dominant site of self-organisation. What is more realistic is a scenario in which trade unions are a part of an alliance of groups that represent worker interests and enter into cooperations with specific crowdworker organisations and ad hoc movements that will, in all likelihood, develop once this form of employment will have expanded.29 Understanding the dynamics of such a scenario would require further research. 


\section{REFERENCES}

Al-Ani, A. (2013). Widerstand in Organisationen. Organisationen im Widerstand. Virtuelle Plattformen, Edupunks und der nachfolgende Staat. Wiesbaden: Springer VS.

Al-Ani, A. (2014). Crowd Union. Gewerkschaften als Plattform. Retrieved on November 12, 2015 from Netzpiloten at

http://www.netzpiloten.de/crowd-union-gewerkschaften-als-plattform/

Al-Ani, A. (2015). Chancen und Risiken Crowdworking. AiB extra. September 2015, 10-13.

Al-Ani, A. (2016). Lehren in digitalen Lernwelten. Neue Rollen und Funktionen von Lehrenden. In Cendon, E., Mörth, A. \& Pellert, A. (Eds.): Theorie und Praxis verzahnen. Lebenslanges Lernen an Hochschulen. Ergebnisse der wissenschaftlichen Begleitung des Bund-LänderWettbewerbs Aufstieg durch Bildung: offene Hochschulen. Münster: Waxmann, 247-26o.

Al-Ani, A., Stumpp, S. and Schildhauer, T. (2014). Crowd-Studie 2014 - Die Crowd als Partner der deutschen Wirtschaft. HIIG Discussion Paper Series No. 2014-O2.

Al-Ani, A., \& Stumpp, S. (2015). Arbeiten in der Crowd. Generelle Entwicklungen und gewerkschaftliche Strategien. Retrieved on November 11, 2015 from verdi.de at https://innovation-gute-

arbeit.verdi.de/themen/crowdworking/++co++7b44a2f2-6112-11e5-9c67-52540059119e

Ashford, S. J., George, E., \& Blatt, R. (2007). Old Assumptions, New Work: The Opportunities and Challenges of Research on Nonstandard Employment. The Academy of Management Annals, 2007(1), 65-117.

Bauwens, M. (2005). Equality, Hierarchy, Freedom. Retrieved on November 10, 2015 at http://p2pfoundation.net/4.2.B._Equality,_Hierarchy,_Freedom

Bauwens, M. (2015). Netarchical Capitalism. Retrieved on November 11, 2015 at http://p2pfoundation.net/Netarchical_Capitalism

Bauwens, M., Mendoza, N., \& Iacomella, F. (2012). Report: Synthetic Overview of The

Collaborative Economy. Retrieved on November 10, 2015 at

http://p2pfoundation.net/Synthetic_Overview_of_the_Collaborative_Economy

Benkler, Y. (2006). The Wealth of Networks. How Social Production Transforms Markets and Freedom. New Haven: Yale University Press.

Bollier, D. (2014, November 2014). News and Perspectives on the Commons. Retrieved on November 13, 2015 at http://bollier.org/blog/commons-growing-global-movement

Bucher E., \& Fieseler, C. (2015). Motive für das digital vermittelte Teilen von Gebrauchsgütern. Marketing Review St. Gallen, 2015(4), 68-74.

Bucher, E., Fieseler, C., \& Hoffmann, C. (2015). Unfairness by Design? Examining Institutionalized Inequality on Digital On-Demand Service Platforms. Norwegian Business School BI Working Paper (in print).

Cella, G.P. (2012). The Representation of Non-Standard Workers. Theory and Culture of 
Collective Bargaining. European Review of Labour and Research, 18(2), 171-184.

Collins, R. (2002). Credential Inflation and the Future of Universities. In: Brint, S. (Ed.): The Future of the City of Intellect. Palo Alto (CA): Stanford University Press, 23-46.

Crawford, K. (2015). Can an Algorithm be Agonistic? Ten Scenes from Life in Calculated Publics. Science, Technology \& Human Values, 41(1). 1-16.

Davies, A. (2015). The EPA Opposes Rules That Could've Exposed VW's Cheating. In: Wired, September 2015. Retrieved on November 13, 2015 at http://www.wired.com/2015/o9/epa-opposes-rules-couldve-exposed-vws-cheating Deutschmann, C. (2002). Postindustrielle Industriesoziologie. Theoretische Grundlagen. Arbeitsverhältnisse und soziale Identitäten. Weinheim and München: Beltz Juventa.

European Union (2016). Communication from the Commission to the European Parliament, the Council, the European Economic and Social Committee and the Committee of the Regions: A European Agenda for the Collaborative Economy. Retrieved on June 10, 2016 at http://ec.europa.eu/danmark/documents/alle_emner/okonomisk/160602_com_2016_356_f1 _communication_from_commission_to_inst_en_v9_p1_851616.pdf

Felstiner, A. (2011). Working the Crowd: Employment and Labor Law in the Crowdsourcing Industry. Berkeley Journal of Employment \& Labor Law, 32(1), 143-203.

Hagel, J., Brown, J. S., \& Davision, L. (2010). The Power of Pull. How Small Moves, Smartly Made, Can Set Big Things in Motion. New York: Basic Books.

Hall, J., \& Krueger, A. (2015). An Analysis of the Labor Market for Uber's Driver Partners in the United States. IRS Working Papers No 587, Princeton: Princeton University.

Hamel, G. (2007). The Future of Management. Boston: Harvard Business School Publishing.

Handelsblatt (2014). Natürlich erzeugt das Aufregung. Retrieved on November 11, 2015 at http://www.handelsblatt.com/unternehmen/handel-konsumgueter/uber-westeuropa-chef-in-d eutschland-sind-alle-fahrten-versichert/10337470-2.html

Handelsblatt (2015). Wir versuchen, die Schwachen zu schützen. 4./5./6. December 2015, Nr. 235, 60-61.

Holloway, J. (2005). Change the World without Taking Power. The Meaning of Revolution Today. London: Pluto Press.

Irani, L., Silberman, M. S. (2013). Turkopticon: Interrupting Worker Invisibility in Amazon Mechanical Turk. Proceedings of the SIGCHI Conference on Human Factors in Computing Systems, 611-620.

Jemielniak, D. (2014). Common Knowledge. An Ethnography of Wikipedia. Palo Alto (CA): Stanford University Press.

Kamenetz, A. (2010). Edupunks, Edupreneurs, and the Coming Transformation of Higher Education. White River Junction (VT): Chelsea Green.

Kessler, S. (2015). True Love is Waiting for You on Uber, Yelp, Quizup and All Other Apps. 
Apps That Aren't Meant For Dating Are Always Used for Dating. That's a Good Thing-For Dating And For Apps. Retrieved on November 10, 2015 at http://www.fastcompany.com/3049510/tech-forecast/true-love-is-waiting-for-you-on-uber-yel p-quizup-and-all-your-other-apps

Knowledge@Wharton (2011, March 16). In Search of the Perfect Search: Can Google Beat Attempts to Game the System? Retrieved on October 14, 2015 at http://knowledge.wharton.upenn.edu/article/in-search-of-the-perfect-search-can-google-beatattempts-to-game-the-system/.

Lee, E. (1997). The Labour Movement and the Internet: The New Internationalism, London: Pluto Press.

Manjoo, F. (2015, January 28). Uber's Business Model Could Change Your Work. New York Times.

Meyer, J. B. (2014, September 26). IBM macht Ernst mit Crowdworking. Computerwoche. Retrieved on November 13, 2015 at

http://www.computerwoche.de/a/ibm-macht-ernst-mit-crowdworking,3068119.

Noveck, B. S. (2009). Wiki Government. How Technology Can Make Government Better, Democracy Stronger, and Citizens More Powerful. New York: Brookings Institution Press.

P2P Foundation (n.d.a.). Transitioning Towards a Commons-Based, Peer-to-Peer Society. Retrieved on May 20, 2016 at https://p2pfoundation.net/

Piech, C., Huang, J., Chen, Z., Do, C., Ng, A., \& Koller, D. (2013). Tuned Models of Peer Assessment in MOOCs. In: Proceedings of The 6th International Conference on Educational Data Mining (EDM 2013). Retrieved on November 10, 2015 at http://web.stanford.edu/ cpiech/bio/papers/tuningPeerGrading.pdf

Rosenblat, A., \& Stark, L. (2015). Uber's Drivers: Information Asymmetries and Control in Dynamic Work. Retrieved on November 15, 2015 at

SSRN: http://ssrn.com/abstract=2686227 doi: 10.2139/ssrn.2686227

Salehi, L., Irani, M., Bernstein, A., Alkhatib, E., Ogbe, E. Milland, K., \& Clickhappier (2015). We Are Dynamo: Overcoming Stalling and Friction in Collective Action for Crowd Workers. Proceedings of CHI 2015. Retrieved on November 2, 2015 from http://hci.stanford.edu/publications/2015/dynamo/DynamoCHI2015.pdf

Schneider, N. (2015, October 12). The New Guilded Age. The New Yorker. Retrieved on November 13, 2015 at http://www.newyorker.com/business/currency/the-new-guilded-age

Scholz, T. (2016). Platform Cooperativism. Challenging the Corporate Sharing Economy. Retrieved on May 19, 2016 at http://www.rosalux-nyc.org/wp-content/files_mf/scholz_platformcooperativism_2016.pdf Send, H., Friesike, S., \& Zuch, A. C. (2014). Participation in On-Line Co-Creation: Assessment and Review of Motivations, HIIG Discussion Paper Series No. 2014-O1.

Shirky, C. (2008). Here Comes Everybody. The Power of Organizing Without Organizations. New York: Penguin Books. 
Shirky, C. (2010). Cognitive Surplus, How Technology Makes Consumer Into Collaborateurs. New York: Penguin Books.

Siegmund-Schultze, N., \& Hibbeler, B. (2011). Initiative gegen überflüssige Operationen: Zweitgutachten per Fernberatung. Deutsches Ärzteblatt 2011; 108(34-35): A-1776 / B-1516 / C1511. Retrieved on November 11, 2015 at http://www.aerzteblatt.de/archiv/102971/Initiative-gegen-ueberfluessige-Operationen-Zweitgu tachten-per-Fernberatung

Skapinker, M. (2015). Unions Suffer for Lack of Killer App Amid Rise of Sharing Economy. Financial Times. Retrieved on November 13, 2015 at http://www.ft.com/intl/cms/s/o/b108eo26-a24d-11e4-bbb8-00144feab7de.html\#axzz3qnu1wi fC

Tepe, D., \& Hepp, A. (2008). Digitale Produktionsgemeinschaften. Die Open-Source-Bewegung zwischen kooperativer Softwareherstellung und deterritorialer Vergemeinschaftung. In:

Stegbauer, C. and Jäckel, M. (Eds.): Social Software. Formen der Kooperation in computerbasierten Netzwerken. Wiesbaden: VS, 27-49.

Towers Watson (2012). 2012 Global Workforce Study. Engagement at Risk: Driving Strong

Perfomance in a Volatile Global Environment. Retrieved on November 13, 2015 at www.towerswatson.com/Insights/IC-Types/Survey-Research-Results/2012/o7/2012-TowersWatson-Global-Workforce-Study

Van der Linden, M. (2015). The Crisis of World Labour. Retrieved on November 13, 2015 at https://solidarity-us.org/site/node/4424

Virno, P. (2010). Exodus. Wien: Turia+Kant.

\section{FOOTNOTES}

1. For a comprehensive overview of the state of the research, see Bucher, Fieseler and Hoffmann (2015, pp. 3ff). For more on the emerging (triangular) working relations between crowdworker, platform and client, see Al-Ani and Stumpp (2015, pp. 42 ff.).

2. For more on the motivational factors of online participation, see Send et al. (2014).

3. For more on the modes of operation of P2P platforms see Bauwens et al. (2012, pp. $156 \mathrm{ff}$ ). Benkler (2006) coined the term "peer production", which can be defined as follows: "What we are seeing now is the emergence of more effective collective action practices that are decentralized but do not rely on either the price system or a managerial structure for coordination." (op. cit., p. 63)

4. In Germany, 19 percent of companies cooperate with the crowd in one or more business functions (Al-Ani, Stumpp and Schildhauer, 2014, pp. 4 ff.).

5. For more on (second) medical reports via platforms, see Siegmund-Schultze and Hibbeler (2011). For more on the evaluation of student papers by peers on the platform Coursera, see Piech et al. (2013).

6. For example, the manager of Uber Germany stated clearly: "We are not a taxi company. It's not our job to buy cars and hire drivers; we just provide the technology platform that enables these transport services." (Handelsblatt 2014, own translation) 
7. "In cases of conflict between requesters and workers, many interviewees express a wish for clearly defined dispute resolution and arbitration processes. Many consider the platform provider a neutral party that could be appealed to in cases of conflict. In its communication with workers, the platform provider does in fact claim a neutral position in that it refuses to interfere in conflicts. However, the processes established and designed by the provider are in fact far from neutral in their effect. The lack of a means of recourse for workers in cases of unfair treatment by requesters is a setting determined by the design of the mediating platform." (Bucher, Fieseler and Hoffmann, 2015, p. 20)

8. Benklers' analysis (2006) was especially ground-breaking in this regard. For a popular scientific account, see Shirky (2008, 2010).

9. For Uber, see the Uber-financed study by Hall and Krueger (2015). For a study on Amazon Mechanical Turk, see Bucher, Fieseler and Hoffmann (2015).

10. For more here, see Shirky (2008, pp.132-133). See Tepe and Hepp's interviews (2008, pp. $30 \mathrm{ff}$.) with programmers from open software platforms. For programmers engaging in unpaid work, the fun of programming and collegial appreciation are the most important aspects: "I once wrote a small patch for a Linux kernel and, well, it is quite flattering when you get questions and suggestions or simply a 'Hey, thank you' or something like 'Good work'. It's motivating to hear that every now and then, yes.” (op. cit., p. 33, own translation)

11. So, it seems that even for commercial and less complex platform tasks, fun still prevails as the main motivator: a survey on the platform Amazon Mechanical Turk revealed that "the first and largest type of participants (44 per cent) are the hedonists, who are characterised by strong fun-oriented motives. Sharing with others is a stimulating and interesting experience for hedonistic sharers. Although monetary compensation plays a certain role for them, hedonists are not primarily materialistic or motivated by profit. Instead, hedonistic participants in sharing platforms are always looking for small-scale adventures and new experiences.” (Bucher and Fieseler, 2015, p. 70). Still, with increasing commercialisation, one might expect remuneration to become increasingly important. This already seems to be the case for the Uber platform (Hall and Krueger, 2015, p. 11). However, all platforms simultaneously act as social networks and so it is perhaps not surprising that even commercially oriented platforms always also seem to offer social opportunities: "Two people heading to the same strip of bars, the same concert or the same sports event are now forced to converse. Small talk breeds questions. Answers determine chemistry. With geographic proximity and mutual interests out of the way, all you have to do is score on the last variable: mutual attraction. You win there, and your UberPool turns into speed dating." (Kessler, 2015)

12. At Amazon's Turk platform, for example: "A number of respondents describe their platform engagement as a regular, ongoing occupation. As these workers become engaged on the platform for longer periods of time, they wish more for opportunities of advancement or perks that come with seniority, such as primary access to tasks. Many seasoned workers provide valuable and frequently uncompensated services for the platform, such as coaching newcomers, helping requesters improve task designs, and identifying violations of platform norms. Some even design and maintain forums and custom feedback software.[...] As the worker community active on the platform becomes more engaged, personalized, and humanized, it becomes more difficult to frame its services as a form of near-instantaneous on-demand computation.” (Bucher, Fieseler, and Hoffmann, 2015, pp. 21-22.)

\section{URL: www.jovoto.com}


14. This may also be a feature of the creative platforms, which are more person-centred and less likely to consider their participants to be an interchangeable factor of production that may be replaced by a machine later (Uber and the self-driving car).

15. For more on this flexibility of the platforms, see Felstiner (2011, p. 154).

16. For more on the discrepancy between demands, expectations and actual responses to concerns, see the experience of the self-organised crowdworker platform Weraredynamo.org in Salehi et al. (2015).

17. See here the collaboration of Uber drivers and the formation of their own "trade unions" based on communities of interest in the United States (Al-Ani, 2014; Al-Ani and Stumpp, 2015, pp. 36-37). Turkopticon also provides an independent technical add-on for the internet browser to assess the so-called requester - i.e. the client - on the efficiency platform Amazon Mechanical Turk. This primarily helps the crowd to identify unfair clients (Irani and Silberman, 2013).

18. ver.di has been organising freelancers for 15 years - including crowdworkers - and advises them here. But it is only since 2015 that crowdworkers have been specifically addressed - by the metalworkers union IG Metall and by ver.di. Since 2015, it has also been possible for freelancers to join IG Metall.

19. "Efforts stalled - lost momentum - when consensus building [...] became too labor-intensive to sustain worker engagement. [...] Friction seemed inevitable when a proposed future affected people in different ways and evoked anxieties of worst-case outcomes. Stalling and friction linked: efforts stalled when friction accumulated or when fear of criticism led to no activity." (Salehi et al., 2015, p. 2)

20. The "bittersweet" assessment of their situation and the possibilities of crowdworking, which has already been noted by other surveys, was also the topic of the crowdstorm contest of the creative crowdworkers on the jovoto platform. The distance from customers and the theft of ideas by competitors are seen as especially problematic. For more on this contest see:

https://verdi.jovoto.com/ideas (as of 12/11/2015).

21. Uber drivers in California are partnering with the Transportation Union to create the AppBased Drivers Association (ABDA), a group that will push Uber to provide better wages and working conditions and give the contractors a stronger voice (Al-Ani, 2014; Al-Ani and Stumpp, 2015, pp. 36-37). This development seems to be in line with the findings of this survey: Uber drivers initially self-organised for a better bargaining position but were turned down by Uber management. Only after teaming with an established union, management engaged in discussions. The emerging working models seems to be that crowd workers organise themselves initially and then cooperate with unions in specific situations requiring specialised skills (negotiation and legal expertise and authority). Furthermore, in the US, crowdworkers are considered as independent contractors. As a result, these workers would not be able to form a traditional union. Instead they would have to form an association, which would have limited bargaining abilities and be allowed to speak on the behalf of drivers.

22. "The question is whether the existing international trade union movement can meet these challenges. It is likely that a new spurt in union development will be a difficult process, interspersed with failed experiments and moments of deep crisis. Organisational structures and patterns of behaviour that have existed for over a century are not easily changed. Moreover, it is 
highly unlikely that new structures and patterns will be shaped through reforms from above, through the central leadership. If there is one thing that history has taught us, it is that trade union structures almost never develop smoothly by means of piecemeal engineering. They are generally the outcome of conflicts and risky experiments. Pressure from below through competitive networks, alternative action models, etc. will be a highly important factor in deciding that outcome. What forms those pressures will take, and whether they will be sufficient to bring about major changes, no one can say yet with any certainty." (Van der Linden, 2015) For the digital transformation of the traditional political institutions and new interfaces to the political crowd see Al-Ani (2013, pp. 221-270).

23. For more on individualised learning paths, which are composed of conventional educational programmes, but also of practical experience and self-organised learning communities, see Kamenetz (2010) and Al-Ani (2016). It has long been clear that traditional IT training courses, for instance, are only partially suitable for practice: “[...] the skills of the cutting-edge high-tech industries such as computers, are generally learned on the job or through personal experience rather than in the formal bureaucratic setting of schooling." (Collins, 2002, p. 26)

24. For more on the option "exit" as opposed to the option "voice" in the virtual world of work, see Virno (2010), who views exit as an option "[...] where we produce something in fleeing to defend social relations and new forms of life . [...] " (op. cit.: 30, own translation) For unions, of course, supporting the exit strategy is quite new. When faced with this possible role for unions, a board member of ver.di replied: "We will not collect venture capital." (Handelsblatt, 2015, p. 60 ). For first examples of unions supporting the setup of new cooperative business platform models see Scholz (2016, p. 17).

25. This is a very typical strategy for the crowd, which can always organise itself and become active: "Doing is practical negation. Doing changes negates an existing state of affair. Doing goes beyond, transcends." (Holloway, 2005, p. 25)

26. Based on the example of the car industry, see the issue of VW publicly opening its software in Davies (2015),

27. It is necessary to deal with the algorithm sensitively, because it may potentially be subject to "gaming the system" or manipulation. "If Google became more transparent, it might become easier to trick [...]. When spammers knew the features of search engines at Yahoo and elsewhere, they gamed the system." (Knowledge@Wharton, 2011). Crawford (2015, p. 11) is very sceptical when it comes to the success of "disappointingly limited calls for algorithmic transparency". She instead advocates for "agonistic algorithms" that make transparent the different motivations and interests of constituents.

28. For first steps to regulate the "Shared Economy" in Europe see European Union (2016).

29. On the co-optation/cooperation of such new collaborations and self-organisation bodies by traditional organisations, see Al-Ani (2013, pp. 260 ff.). 